\title{
Precambrian ocean-atmosphere evolution based on the Archive of sedimentary pyrite
}

\author{
ROSS R LARGE AND INDRANI MUKHERJEE
}

University of Tasmania

Presenting Author: Ross.Large@utas.edu.au

Sedimentary pyrite which grows in the water column or in the first few centimetres on the seafloor encapsulates a wide range of trace elements in proportion to their abundance in the coeval seawater. Thus, by measuring the concentration, by LA-ICP-MS, of 25 trace elements in carefully screened sedimentary pyrites deposited through time, we have been able to track the first order trends in the chemistry of the global ocean (Large et al., 2014; Gregory et al., 2015). These trends in the critical nutrient elements including $\mathrm{Ni}, \mathrm{Co}, \mathrm{Zn}$, Mo and Se have likely played a significant role in prokaryote and eukaryote evolution, supporting the concept that rather than a flat boring period, the Late Paleoproterozoic and Mesoproterozoic was a period of significant change in the oceans (Mukherjee et al., 2018; Mukherjee and large, 2020). Because many of the measured trace elements are redox sensitive or sensitive to oxidative weathering, then we can also speculate on trends in atmosphere oxygenation using our extensive pyrite database through the Precambrian (Steadman et al. 2020). This approach has led us to refining the profile for atmosphere oxygen, with the conclusion that the GOE, rather than a geologically rapid oxygen rise, was in-fact a gradual rise, commencing around $2800 \mathrm{Ma}$ and rising to a peak at about $1800 \mathrm{Ma}$, before declining through most of the Mesoproterozoic. Many other redox proxies including mineral evolution (Hazen et al 2018), carbon-isotopes, $\mathrm{N}$-isotopes, Fe-isotopes, black shale thickness and fossil size support the theory that atmosphere oxygen was at a peak from 2000 to $1750 \mathrm{Ma}$.

Gregory et. al (2015) Economic Geology, 110, 1389-1410

Hazen et al (2008) Am. Mineral, 93 (11-12)1693-1720.

Large et al. (2014) EPSL, 389, 209-220.

Mukherjee and Large (2020) Geology, 48 (10) 1018-1022.

Mukherjee et al (2018) Sci Rep, 8 (1) 1-7.

Steadman et al (2020) Prec Res, 343, 105722 